BNL-114030-2017-JA

\title{
Designing Air-Stable O3-Type Cathode Materials by Com-bined Structure Modulation for Na-Ion Batteries
}

H.-R. Yao, P.-F. Wang, Y. Gong, J. Zhang, X. Yu, L. Gu, C. OuYang, Y.-X. Yin, E. Hu, X.-Q. Yang, E. Stavitski, Y.-G. Guo, and L.-J. Wan

Submitted to Journal of American Chemical Society

June 2017

Chemistry Department

Brookhaven National Laboratory

\section{U.S. Department of Energy USDOE Office of Energy Efficiency and Renewable Energy (EERE)}




\section{DISCLAIMER}

This report was prepared as an account of work sponsored by an agency of the United States Government. Neither the United States Government nor any agency thereof, nor any of their employees, nor any of their contractors, subcontractors, or their employees, makes any warranty, express or implied, or assumes any legal liability or responsibility for the accuracy, completeness, or any third party's use or the results of such use of any information, apparatus, product, or process disclosed, or represents that its use would not infringe privately owned rights. Reference herein to any specific commercial product, process, or service by trade name, trademark, manufacturer, or otherwise, does not necessarily constitute or imply its endorsement, recommendation, or favoring by the United States Government or any agency thereof or its contractors or subcontractors. The views and opinions of authors expressed herein do not necessarily state or reflect those of the United States Government or any agency thereof. 


\title{
Designing Air-Stable O3-Type Cathode Materials by Com- bined Structure Modulation for Na-Ion Batteries
}

\author{
Hu-Rong Yao, , $\neq$ Peng-Fei Wang, ${ }^{\dagger, \ddagger}$ Yue Gong, ${ }^{\S}$ Jienan Zhang,, Xiqian Yu, ${ }^{\S}$ Lin Gu, ${ }^{\S . \ddagger}$ Chuying

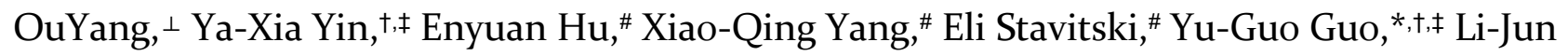 \\ Wan, ${ }^{+, \neq}$
}

${ }^{\dagger}$ CAS Key Laboratory of Molecular Nanostructure and Nanotechnology, CAS Research/Education Center for Excellence in Molecular Sciences, Institute of Chemistry, Chinese Academy of Sciences (CAS), Beijing 10o19o, China

§Beijing National Laboratory for Condensed Matter Physics, Institute of Physics, CAS, Beijing 10019o, China

${ }^{\perp}$ Laboratory of Computation Materials Physics, Department of Physics, Jiangxi Normal University, Nanchang, 330022, China

‡University of Chinese Academy of Sciences, Beijing 100049, China

\#Brookhaven National Laboratory, Upton, New York 11973, USA

Supporting Information

\begin{abstract}
As promising high-capacity cathode materials for Na-ion batteries, $\mathrm{O}_{3}$-type Na-based metal oxides always suffer from their poor air stability originating from the spontaneous extraction of $\mathrm{Na}$ and oxidation of transition metals when exposed to air. Herein, a combined structure modulation is proposed to concurrently tackle the two handicaps via reducing $\mathrm{Na}$ layers spacing and simultaneously increasing valance state of transition metals. Guided by density functional theory calculations, we demonstrate that such a modulation can be subtly realized through co-substitution of one kind of heteroatom with comparable electronegativity and another one with substantially different Fermi level, by adjusting the structure of $\mathrm{NaNi}_{0.5} \mathrm{Mn}_{0.5} \mathrm{O}_{2}$ via $\mathrm{Cu} / \mathrm{Ti}$ codoping. The as-obtained $\mathrm{NaNi}_{\text {o. }} \mathrm{Cu}_{\text {o.o5 }} \mathrm{Mn}_{0.4} \mathrm{Ti}_{0.1} \mathrm{O}_{2}$ exhibits an increase of 20 times in stable air-exposure period and 9 times in capacity retention after 500 cycles, and even retains its original structure and capacity after being soaked in water. Such a simple and effective structure modulation reveals a new avenue for developing high-performance $\mathrm{O}_{3}$-type cathodes and pushes the large-scale industrialization of $\mathrm{Na}$-ion batteries a decisive step forward.
\end{abstract}

Large-scale energy storage systems have attracted increasing interest recently, since they are regarded as one of the greatest challenges for the development of smart electrical grid. ${ }^{1}$ The large demand and cost considerations may require the application of Na-ion batteries (NIBs) rather than Li-ion batteries, ${ }^{2}$ due to the abundance and wide distribution of Na. ${ }^{3}$ Recently, great efforts have been devoted to improve the overall performance of NIBs, in which the advancements of cathode materials play a crucial role. ${ }^{4}$

Among various cathode candidates, O3-type Na-based layered transition metal oxides $\mathrm{NaTMO}_{2}$ (where TM=transition metal, e.g., $\mathrm{Co}, \mathrm{Ni}, \mathrm{Mn}, \mathrm{Fe}$, etc. $)^{5}$ are considered as one of the most appealing candidates due to their good electrochemical activity and simple synthesis process. ${ }^{6}$ However, when exposed to air, the capacity of $\mathrm{O}_{3}$-type cathodes are rapidly reduced originating from the spontaneous extraction of $\mathrm{Na}$, oxidation of transition metals, and the concurrent transition to Na-deficient phases. ${ }^{7}$ The poor air stability greatly raises the cost for material storage, transportation, and battery manufacture, and thus limits the practical applications of O3-type oxides. ${ }^{8}$ At present, the rational strategies for improving the air stability of $\mathrm{O}_{3}-\mathrm{Na}_{\mathrm{x}} \mathrm{TMO}_{2}$ have not been well developed. Therefore, the systematic research is urgently needed regarding to the mechanism governing improved air stability, in order to guide the design and development of O3-type cathode materials with both good air stability and excellent electrochemical properties.

Herein, a combined structure modulation is proposed to effectively improve the air stability of $\mathrm{O}_{3}$-type metal oxides via reducing the interlayer distance of Na layers and simultaneously increasing valance state of transition metals. Guided by density functional theory (DFT) calculations, we demonstrate that such a modulation can be subtly realized through co-substitution of one kind of heteroatom with comparable electronegativity and another one with substantially different Fermi level, by adjusting the structure of $\mathrm{NaNi}_{0.5} \mathrm{Mn}_{0.5} \mathrm{O}_{2}$ (NaNM) via $\mathrm{Cu} / \mathrm{Ti}$ co-substitution. Due to effective suppression of spontaneous $\mathrm{Na}$ extraction and improvement of inoxidizability, the as-obtained $\mathrm{NaNi}_{0.45} \mathrm{Cu}_{0.05} \mathrm{Mn}_{0.4} \mathrm{Ti}_{0.1} \mathrm{O}_{2}$ (NaNCMT) exhibits an increase of 20 times in stable airexposure period, and even retains its original structure and capacity after being soaked in water. In addition, the electrochemical properties are significantly improved upon the combined modulation as the suppression of charge ordering and complicated phase transitions during cycling.

First DFT calculations were performed to examine feasibility of the combined structure modulation. Due to the substantial difference in Fermi level between $\mathrm{Ti}^{4+}$ and $\mathrm{Ni}^{2+} / \mathrm{Mn}^{4+}$, substituting a small number of $\mathrm{Mn}^{4+}$ with $\mathrm{Ti}^{4+}$ is effective for preventing charge ordering and decreasing the electronic localization. 9 The electronic delocalization results in expansion of TM layers and contraction of Na layer spacing, associated with decrease in interaction between TM and $\mathrm{O}$, and enhancement of the binding energy between Na and O.9 DFT calculations predict that contraction of $\mathrm{Na}$ layer spacing in NaNM is accessible via Ti substitution (Figure 1a), which is in 
excellent agreement with the results of X-ray diffraction (XRD) refinement of $\mathrm{NaNM}$ and $\mathrm{NaNi}_{\mathrm{O} .5} \mathrm{Mn}_{\mathrm{O} .4} \mathrm{Ti}_{\mathrm{O} .1} \mathrm{O}_{2}$ (NaNMT) (Figure $\mathrm{S}_{1}$, Table $\mathrm{S}_{1}, \mathrm{~S}_{2}$ ). Furthermore, Ti substitution effectively increases the valance state of $\mathrm{Ni}$ because the electronic delocalization decreases the number of electrons around $\mathrm{Ni}$ (Figure $1 b$ ). In addition, a mixing transition metal method ${ }^{10}$ was applied to further increase the valance state of $\mathrm{Ni}$. The deformation of $\mathrm{TMO}_{6}$ octahedrons and rearrangement of electrons were achieved with heterogeneous transition metal doping. Considering the electronegativity and electrochemical activity, $\mathrm{Cu}$ were introduced into this system, ${ }^{11}$ and the increase in valance state of Ni was also indicated (Figure $1 \mathrm{~b}$ ). The increase in $\mathrm{Ni}$ valance state upon $\mathrm{Cu} / \mathrm{Ti}$ co-substitution was also experimentally confirmed by X-ray photoelectron spectroscopy (XPS) (Figure S2). The results of DFT calculations demonstrate that the structure modulation for NaNM, contracting Na layer spacing and increasing the valence state of $\mathrm{Ni}$, is accessible via $\mathrm{Cu} / \mathrm{Ti}$ co-substitution in theory.
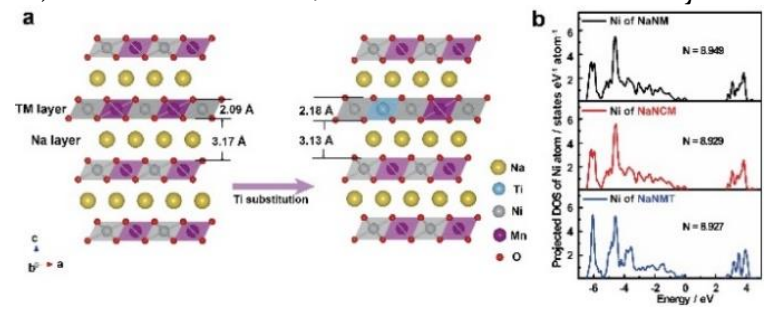

Figure 1. DFT calculations. (a) Comparison of calculated configuration of NaNM and NaNMT. (b) Electronic density of states projected on Ni ion of NaNM, NaNCM, and NaNMT.

Based on the above calculative results, we prepared $\mathrm{NaNi}_{\text {o. } 45} \mathrm{Cu}_{\text {o.05 }} \mathrm{Mn}_{0.4} \mathrm{Ti}_{\text {o.1 }} \mathrm{O}_{2}$ (NaNCMT) and NaNM, which are composed of large particles with several micrometers in dimension (Figure $2 \mathrm{a}$ and $\mathrm{S}_{3} \mathrm{a}$ ). The energy dispersive spectroscopy (EDS) mappings (Figure $2 \mathrm{~b}$ and $\mathrm{S}_{3} \mathrm{~b}$ ) clearly show that various elements uniformly distribute in particles. It can be seen that $\mathrm{Cu} / \mathrm{Ti}$ co-substitution maintains the $\mathrm{O}_{3}$ structure with $R \overline{3} m$ space group (Figure $2 \mathrm{c}, \mathbf{2} \mathrm{d}, \mathrm{S}_{4}$, Table $\mathrm{S}_{2}, \mathrm{~S}_{3}$ ), except for a small amount of $\mathrm{NiO}$ impurity.
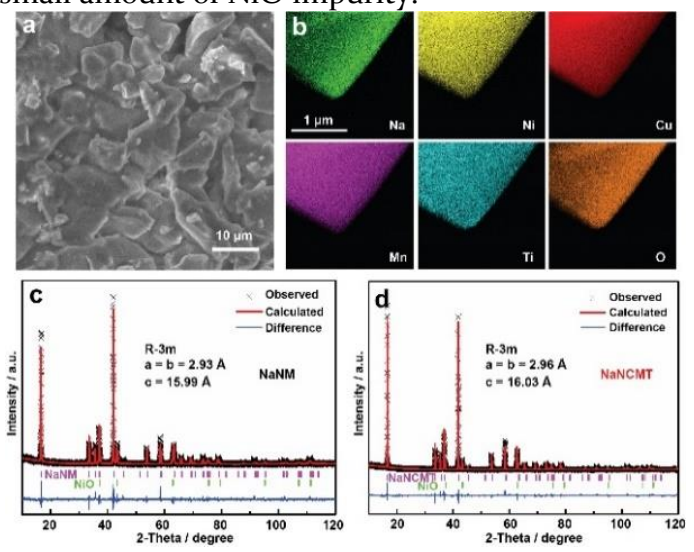

Figure 2. (a) SEM image of NaNCMT. (b) EDS maps of NaNCMT. Rietveld refinement patterns of XRD data for (c) NaNM and (d) NaNCMT.

To test the air stability, aging experiments (exposing materials to air for 2 days or soaking in water for $10 \mathrm{~min}$ followed by drying at $100{ }^{\circ} \mathrm{C}$ overnight) were carried out, and then the structure of pristine and aged materials were compared by XRD measurements. As shown in Figure 3a, NaNM undergoes apparent structure change after aging experiments. The structure change is already observed just after 2 hours of air exposure as the formation of $\mathrm{O}_{3} 3$ and $\mathrm{P}_{3}$-type $\mathrm{Na}_{1-\mathrm{y}} \mathrm{Ni}_{0.5} \mathrm{Mn}_{0.5} \mathrm{O}_{2}$ (Figure $\mathrm{S}_{5}$ ). ${ }^{12}$ The proportion of $\mathrm{Na}$ deficient $\mathrm{P}_{3}$ phase gradually increases with the prolongation of air-exposure time, and the majority of water-soaked material transform into $\mathrm{P}_{3}$ phase (Figure S6), indicating serious destruction of structure in water-soaked material triggered by excessive extraction of $\mathrm{Na}$ and insertion of $\mathrm{H}_{2} \mathrm{O}$ molecules. ${ }^{13}$ In contrast, a small amount of $\mathrm{Cu} / \mathrm{Ti}$ co-substitution is sufficient to inhibit the spontaneous phase transition. The XRD patterns of NaNCMT, whether exposed to air or soaked in water, are nearly identical to that of as-synthesized sample (Figure $3 \mathrm{~b}$ ). In addition, the water-soaked NaNCMT material shows no obvious morphological change compared with the pristine ones (Figure $\mathrm{S}_{7}$ ), indicating the good morphological stability. The improvement of air stability is also exhibited in the electrochemical data. Pristine NaNM shows an initial charge capacity of $106.4 \mathrm{~mA} \mathrm{~h} \mathrm{~g}{ }^{-1}$, however, the aged NaNM delivers a poor charge capacity of approximately $50 \mathrm{~mA} \mathrm{~h} \mathrm{g^{-1 }}$ (Figure $3 \mathrm{c}$ ). It is worth noting that both the discharge capacity of the first cycle and the charge capacity of subsequent cycles approach $100 \mathrm{~mA} \mathrm{~h} \mathrm{~g}^{-1}$ (Figure S8), consistent with the conclusion of extraction of $\mathrm{Na}$ and formation of $\mathrm{Na}_{1-\mathrm{y}} \mathrm{Ni}_{0.5} \mathrm{Mn}_{0.5} \mathrm{O}_{2}$ phases. In contrast, NaNCMT shows high capacity retention after aging experiments (Figure $3 \mathrm{~d}$ ). In addition, owing to the apparent difference in degree of reaction with water between NaNM and NaNCMT, the reaction heats of these two samples and water are also significantly different from each other. Supporting Video shows that with the addition of $5 \mathrm{~g}$ NaNM to $10 \mathrm{~mL}$ water, the temperature of water rises from $24.4{ }^{\circ} \mathrm{C}$ to $30.8{ }^{\circ} \mathrm{C}$, while added with NaNCMT only increases to $24.6{ }^{\circ} \mathrm{C}$ from $24.5^{\circ} \mathrm{C}$.
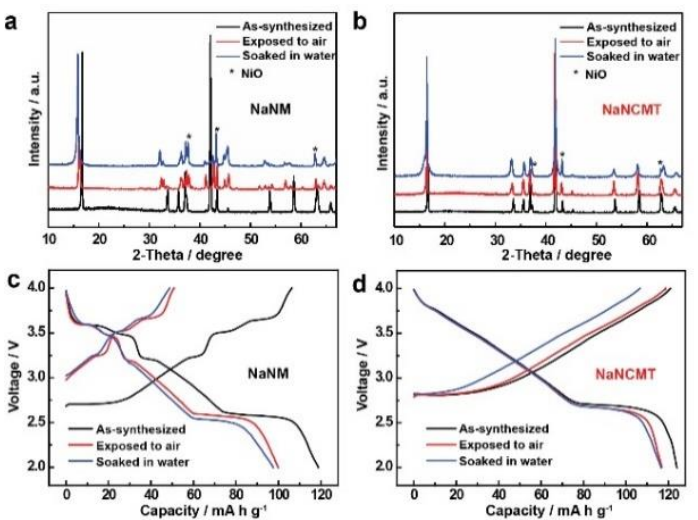

Figure 3. XRD patterns of as-synthesized and aged (a) NaNM and (b) NaNCMT. The first charge/discharge curves of assynthesized and aged (c) NaNM and (d) NaNCMT.

To further obtain information on the aging process of materials, ex-situ XANES data at the $\mathrm{Ni}$ and $\mathrm{Mn} K$-edge were recorded to detect oxidation state changes. The position of $\mathrm{Ni} K$-edge absorption peak of aged NaNM (Figure 4a) obviously shifts to the higher energy region. The shift closely resembles that of the charge process ${ }^{14}$ corresponding to $\mathrm{Ni}$ oxidation. The Mn K-edge spectrum of aged NaNM (Figure 4b) show only a change in shape, implying that the Mn remains at $\mathrm{Mn}^{++}$. The shape change originates from the adjustment in the local coordinational environment of Mn. ${ }^{14}$ In contrast, no shifts of Ni (Figure 4c) or Mn K-edge absorption peak (Figure $4 \mathrm{~d}$ ) are observed in aged NaNCMT, indicating significant improvement of inoxidizability consistent with the predictive results of DFT calculations. 

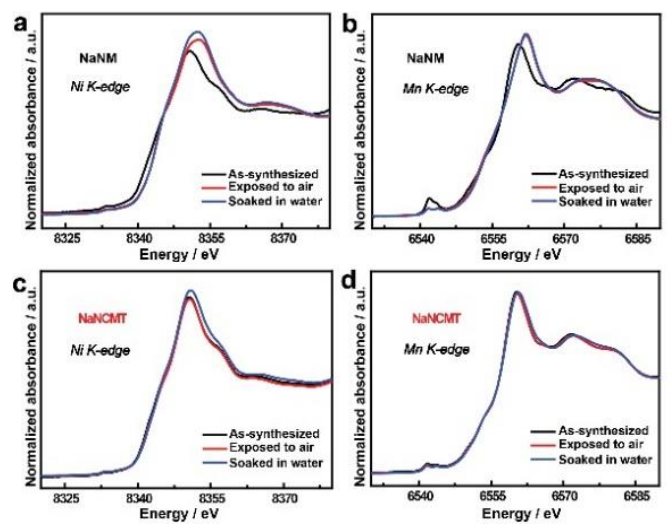

Figure 4. XANES spectra at (a) Ni K-edge and (b) Mn K-edge of NaNM; (c) Ni K-edge and (d) Mn K-edge of NaNCMT.

Furthermore, structures of water-soaked materials were directly identified at atomic-scale by annular bright field (ABF) and high-angle annular dark field (HAADF) STEM. The ABF image of water-soaked NaNM (Figure 5a) shows significant contrast attributed to prismatic coordination sited $\mathrm{Na}$ columns. In particular, the $\mathrm{O}$ columns stack in a head-tohead stacking (ABBCCA) mode of $\mathrm{P}_{3}$ phase. In contrast, water-soaked NaNCMT remained original $\mathrm{O}_{3}$ phase (Figure $5 \mathrm{~b}$ ), verified by the octahedral sites of $\mathrm{Na}$ and $\mathrm{ABCABC}$ stacking model of $\mathrm{O}$ columns. Moreover, in HAADF images, the adjacent layer distance, $d_{c}$, of aged NaNM (Figure $5 \mathrm{c}$ ) is larger than that of NaNCMT (Figure $5 \mathrm{~d}$ ), although the lattice parameter of the $c$-axis of as-synthesized NaNM is smaller than NaNCMT. The increase in $d_{c}$ of water-soaked NaNM is attributable to increased repulsion between adjacent $\mathrm{O}$ layers due to the decreased shielding effect of $\mathrm{Na}$ ions, ${ }^{15}$ which agrees well with the in-situ XRD result.
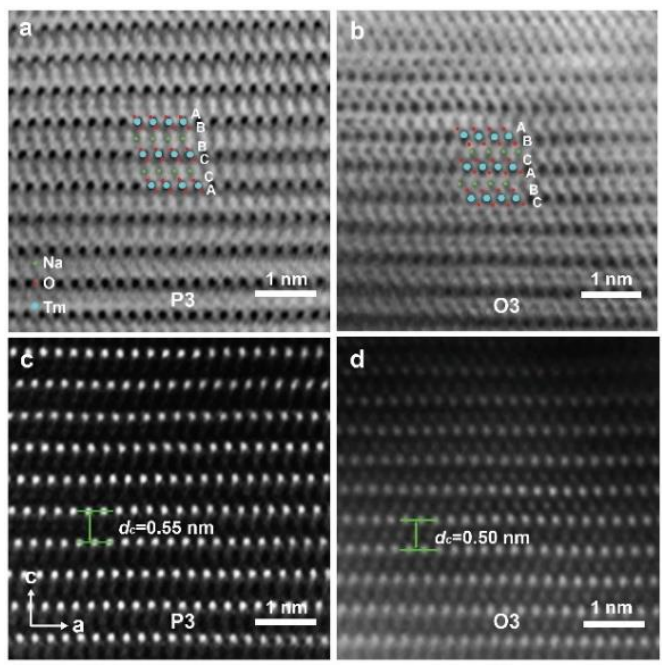

Figure 5. ABF-STEM images of water-soaked (a) NaNM and (b) NaNCMT. HAADF-STEM images of water-soaked (c) NaNM and (d) NaNCMT.

Based on the modulation strategy discussed above, we further designed $\mathrm{Cu} / \mathrm{Sn}$ co-substituted NaNCMS, which also exhibits excellent air stability (Figure S9). As discussed above, the remarkable improvement in air stability is characterized from macro- to micro-scale for $\mathrm{Cu} / \mathrm{Ti}$ co-doping into NaNM, inducing crystal and electronic structure modulation.

Complementing the excellent air stability, the electrochemical properties are also improved upon $\mathrm{Cu} / \mathrm{Ti}$ substitu- tion. As shown in Figure 6a, the discharge/charge curves of NaNM exhibits several plateaus reflecting multiple phase transitions occurring along with $\mathrm{TMO}_{2}$ slab gliding. ${ }^{16}$ In contrast to NaNM, the NaNCMT cathode shows a smoother charge/discharge profile, with a higher initial discharge capacity of $124 \mathrm{~mA} \mathrm{~h} \mathrm{~g}$, originating from electronic delocalization and solid-solution reaction of a large region as discussed below. The open circuit voltages (OCVs) of NaNCMT (2.82 V) was higher than that of NaNM $(2.68 \mathrm{~V})$, implying the increased valence state of $\mathrm{Ni}$ upon $\mathrm{Cu} / \mathrm{Ti}$ co-substitution, consistent with the results of DFT calculations. After 500 cycles at ${ }_{1 C}$ (Figure $6 \mathrm{~b}$ ), the NaNCMT exhibits $70.2 \%$ of capacity retention, which is much higher than that of NaNM $(7.8 \%)$. The Coulombic efficiencies for NaNCMT are always greater than $99 \%$ and more stable than NaNM. Furthermore, NaNCMT cathode exhibits better rate performance shown in Figure 6c. At a rate of $10 \mathrm{C}$, NaNCMT still delivers a capacity as high as $81 \mathrm{~mA} \mathrm{~h} \mathrm{~g}^{-1}$ (Figure 6d). NaNCMT cathode represents highly competitive electrochemical properties, in terms of Coulombic efficiency, energy output values, and rate performance for $\mathrm{O}_{3}$-type cathodes. ${ }^{17}$
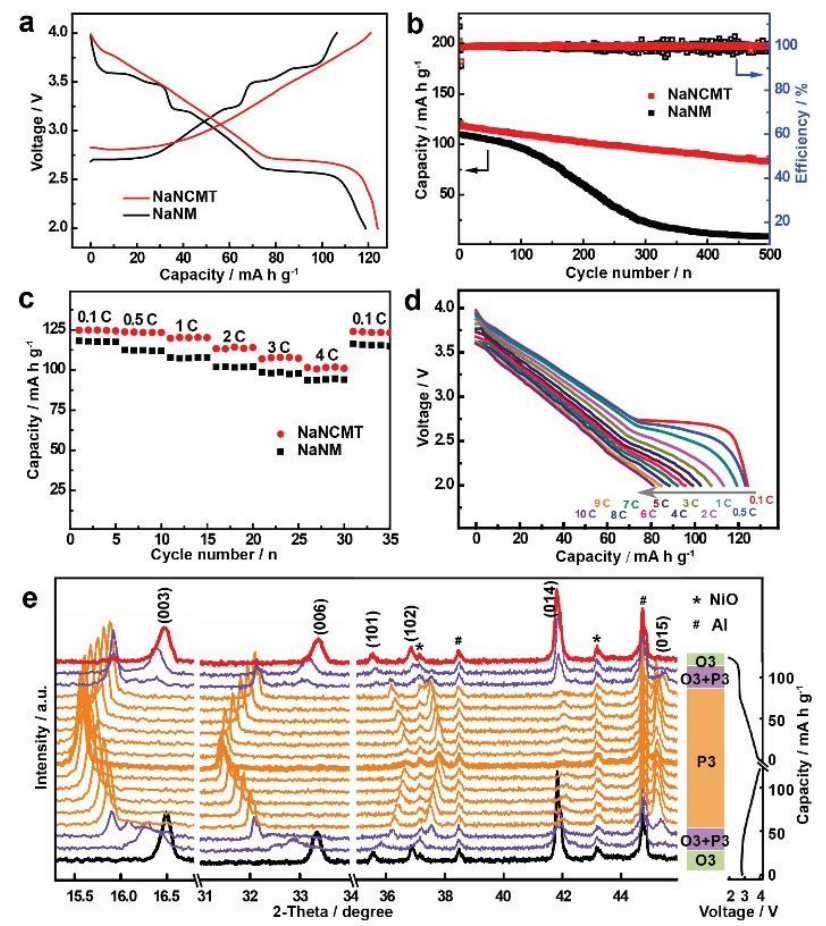

Figure 6. (a) Comparison of the first charge/discharge curves tested at o.1C. (b) Comparison of cycling stability and Coulombic efficiency tested at $1 \mathrm{C}$. (c) Rate performance of samples. (d) Discharge curves of NaNCMT cycled at constant charge at $0.5 \mathrm{C} /$ discharge rates from $0.1 \mathrm{C}$ to ${ }_{10 C}$. (e) In-situ XRD patterns collected during the first charge/discharge process of NaNCMT.

The excellent electrochemical performance discussed above is related to the $\mathrm{Na}$ deintercalation/intercalation mechanism, which was investigated by in-situ XRD pattern evolution (Figure 6e). With initial $\mathrm{Na}$ extraction, the (ооз) peaks of the $\mathrm{O}_{3}$ phase shift to a lower angle and a new $\mathrm{P}_{3}$ phase start to form through a two-phase reaction, corresponding to the low-voltage plateau region. Upon subsequent charge, the $\mathrm{P}_{3}$ phase peaks shift continuously until charged to 4.0 $\mathrm{V}$ with no the appearance of any new peaks, indicating a solid-solution reaction in this large region con- 
sistent with the sloping charge/discharge curves. Upon discharge, the $\mathrm{P}_{3}$ phase transforms back to a single $\mathrm{O}_{3}$ phase, which is an exact opposite evolution of the charge process, indicating the phase transition processes are highly reversible. For the entire charge/discharge cycle of NaNCMT, no monoclinic $\mathrm{O}_{3}^{\prime} 3$ or $\mathrm{P}^{\prime} 3$ phases are observed, which is distinct from the reported $\mathrm{NaNM}^{14}$. The suppression of phase transitions, solid-solution reaction of a large region and diluted $\mathrm{Ni}^{3+}$ characterized by Jahn-Teller distortion result in the significant improvement of electrochemical performances upon $\mathrm{Cu} / \mathrm{Ti}$ substitution.

In summary, a combined structure modulation is suggested and show marked effectiveness to improve the air stability of $\mathrm{O}_{3}$-type cathode materials via reducing the interlayer distance of $\mathrm{Na}$ layers and simultaneously increasing valance state of transition metals, because of the suppression of spontaneous $\mathrm{Na}$ extraction and enhanced inoxidizability. Based on mixing transition metal method and the adjustment of electronic structure, we realize the modulation for $\mathrm{NaNM}$ by the co-substitution of $\mathrm{Cu}^{2+}$ with comparable electronegativity and $\mathrm{Ti}^{4^{+}}$with substantially different Fermi level than $\mathrm{Ni}^{2+} / \mathrm{Mn}^{4+}$. The modulation was clearly demonstrated by a combination of Rietveld refinement, electrochemistry and XPS tests (Na layer spacing contracted from $3.45 \AA$ to $3.37 \AA$, the OCVs increased from $3.68 \mathrm{~V}$ to $3.82 \mathrm{~V}$, and $\mathrm{Ni} 2 p_{1 / 2}$ peak shifted from $871.4 \mathrm{eV}$ to $872.9 \mathrm{eV}$ upon $\mathrm{Cu} / \mathrm{Ti}$ doping). The as-obtained NaNCMT exhibits an increase of 20 times on stable air-exposure period than NaNM, and even retains its original structure and capacity after being soaked in water. Furthermore, charge ordering and complicated phase transitions were both effectively suppressed during cycling, and thus after 500 cycles NaNCMT showed high capacity retention of nine times that of NaNM. The combined structure modulation is simple, yet effective, and paves a way for the development of high-performance $\mathrm{O}_{3}$-type cathodes and will be proved to be a milestone for the massive application of NIBs.

\section{ASSOCIATED CONTENT}

\section{Supporting Information}

The Supporting Information is available free of charge via the Internet at http://pubs.acs.org. More details for experimental and characterizations;

\section{AUTHOR INFORMATION}

\section{Corresponding Author}

*E-mail: ygguo@iccas.ac.cn

Notes

The authors declare no competing financial interest.

\section{ACKNOWLEDGMENT}

This work was supported by the National Key R\&D Program of China (Grant Nos. 2016YFBo10o10o and 2016YFAo202500), the National Basic Research Program of China (Grant No. 2014CB921002), the National Natural Science Foundation of China (Grant Nos. 51225204 and 51522212), and the 'Strategic Priority Research Program' of the Chinese Academy of Sciences (Grant Nos. XDAogo10100 and XDBo7030200), and CAS. The work at Brookhaven National Laboratory was supported by the Assistant Secretary for Energy Efficiency and Renewable Energy, Office of Vehicle Technologies of the U.S. Department of Energy through the Advanced Battery Materi- als Research (BMR) Program, including Battery5oo Consortium, under contract number DE-SCoo12704. The authors acknowledge the technique supports from beamline 8-ID at National Synchrotron Light Source II and beamline BL-14W at Shanghai Synchrotorn Radiation Facility.

\section{REFERENCES}

(1) (a) Ma, C.; Alvarado, J.; Xu, J.; Clement, R. J.; Kodur, M.; Tong, W.; Grey, C. P.; Meng, Y. S. J. Am. Chem. Soc. 2017, 139, 4835; (b) Sun, J.; Lee, H.-W.; Pasta, M.; Yuan, H.; Zheng, G.; Sun, Y.; Li, Y.; Cui, Y. Nat. Nanotechnol. 2015, 10, 980; (c) See, K. A.; Chapman, K. W.; Zhu, L.; Wiaderek, K. M.; Borkiewicz, O. J.; Barile, C. J.; Chupas, P. J.; Gewirth, A. A. J. Am. Chem. Soc. 2016, 138, 328.

(2) (a) Ren, W. H.; Zhu, Z. X.; An, Q. Y.; Mai, L. Q. Small 2017, 1604181; (b) Zhu, Y.; Han, X.; Xu, Y.; Liu, Y.; Zheng, S.; Xu, K.; Hu, L. B.; Wang, C. S. Acs Nano 2013, 7, 6378; (c) Lacey, S. D.; Wan, J.; Cresce, A. v. W.; Russell, S. M.; Dai, J.; Bao, W.; Xu, K.; Hu, L. B. Nano Lett. 2015, 15, 1018; (d) Song, J.; Wang, L.; Lu, Y.; Liu, J.; Guo, B.; Xiao, P.; Lee, J.-J.; Yang, X.-Q.; Henkelman, G.; Goodenough, J. B. J. Am. Chem. Soc. 2015, 137, 2658.

(3) (a) Zhu, C.; Kopold, P.; van Aken, P. A.; Maier, J.; Yu, Y. Adv. Mater. 2016, 28, 2409; (b) Li, Q.; Li, N.; Liu, Y.; Wang, Y.; Zhou, H. S. Adv. Energy Mater. 2016, 6, 1600632; (c) Stratford, J. M.; Mayo, M.; Allan, P. K.; Pecher, O.; Borkiewicz, O. J.; Wiaderek, K. M.; Chapman, K. W.; Pickard, C. J.; Morris, A. J.; Grey, C. P. J. Am. Chem. Soc. 2017, 139, 7273; (d) Liu, Z.; Yu, X.-Y.; Lou, X. W.; Paik, U. Energy Environ. Sci. 2016, 9, 2314.

(4) (a) Dong, Y. F.; Li, S.; Zhao, K. N.; Han, C. H.; Chen, W.; Wang, B. L.; Wang, L.; Xu, B.; Wei, Q. L.; Zhang, L.; Xu, X.; Mai, L. Q. Energy Environ. Sci. 2015, 8, 1267; (b) Xiang, X.; Zhang, K.; Chen, J. Adv. Mater. 2015, 27, 5343.

(5) Guo, S. H.; Liu, P.; Yu, H. J.; Zhu, Y. B.; Chen, M. W.; Ishida, M.; Zhou, H. S. Angew. Chem. Int. Ed. 2015, 127, 5992.

(6) (a) Keller, M.; Buchholz, D.; Passerini, S. Adv. Energy Mater. 2016, 6, 1501555; (b) Oh, S. M.; Myung, S. T.; Yoon, C. S.; Lu, J.; Hassoun, J.; Scrosati, B.; Amine, K.; Sun, Y. K. Nano Lett. 2014, 14, 1620.

(7) (a) Oh, S. M.; Myung, S. T.; Hwang, J. Y.; Scrosati, B.; Amine, K.; Sun, Y. K. Chem. Mater. 2014, 26, 6165; (b) Vassilaras, P.; Toumar, A. J.; Ceder, G. Electrochem. Commun. 2014, 38, 79; (c) Thorne, J. S.; Dunlap, R. A.; Obrovac, M. N. J. Electrochem. Soc. 2013, 160, A361.

(8) Mu, L. Q.; Xu, S. Y.; Li, Y. M.; Hu, Y. S.; Li, H.; Chen, L. Q.; Huang, X. J. Adv. Mater. 2015, 27, 6928.

(9) Wang, Y. S.; Xiao, R. J.; Hu, Y. S.; Avdeev, M.; Chen, L. Q. Nat. Commun. 2015, 6, 6954.

(10) Liu, L.; Li, X.; Bo, S. H.; Wang, Y.; Chen, H.; Twu, N.; Wu, D.; Ceder, G. Adv. Energy Mater. 2015, 5, 1500944.

(11) Li, Y. M.; Yang, Z. Z.; Xu, S. Y.; Mu, L. Q.; Gu, L.; Hu, Y. S.; Li, H.; Chen, L. Q. Adv. Sci. 2015, 2, 1500031.

(12) Sathiya, M.; Hemalatha, K.; Ramesha, K.; Tarascon, J. M.; Prakash, A. S. Chem. Mater. 2012, 24, 1846.

(13) (a) Buchholz, D.; Chagas, L. G.; Vaalma, C.; Wu, L. M.; Passerini, S. J. Mater. Chem. A 2014, 2, 13415; (b) Lu, Z. H.; Dahn, J. R. Chem. Mater. 2001, 13, 1252; (c) Cabana, J.; Chernova, N. A.; Xiao, J.; Roppolo, M.; Aldi, K. A.; Whittingham, M. S.; Grey, C. P. Inorg. Chem. 2013, 52, 8540 .

(14) Komaba, S.; Yabuuchi, N.; Nakayama, T.; Ogata, A.; Ishikawa, T.; Nakai, I. Inorg. Chem. 2012, 51, 6211.

(15) Han, M. H.; Gonzalo, E.; Sharma, N.; del Amo, J. M. L.; Armand, M.; Avdeev, M.; Garitaonandia, J. J. S.; Rojo, T. Chem. Mater. 2016, 28, 106.

(16) Wang, P.-F.; You, Y.; Yin, Y.-X.; Guo, Y.-G. J. Mater. Chem. A 2016, 4, 17660 .

(17) (a) Kim, D.; Kang, S.-H.; Slater, M.; Rood, S.; Vaughey, J. T.; Karan, N.; Balasubramanian, M.; Johnson, C. S. Adv. Energy Mater. 2011, 1, 333; (b) Yuan, D. D.; Wang, Y. X.; Cao, Y. L.; Ai, X. P.; Yang, H. X. ACS Appl. Mater. Interfaces 2015, 7, 8585; (c) Yuan, D. D.; Liang, X. M.; Wu, L.; Cao, Y. L.; Ai, X. P.; Feng, J. W.; Yang, H. X. Adv. Mater. 2014, 26, 6301. 
Graphic TOC

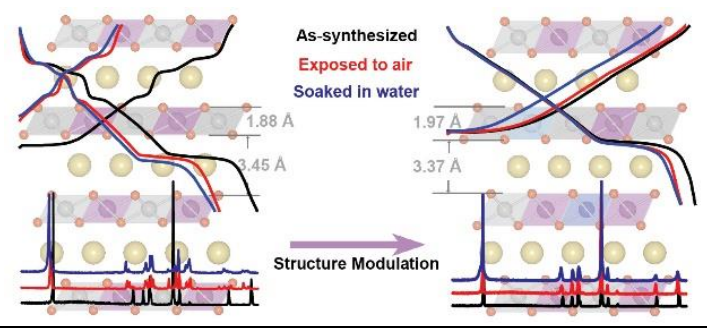

